\title{
Saber y razón en el Neoplatonismo: hacia una nueva comprensión de la filosofía de Jámblico
}

\author{
Knowledge and reason in Neoplatonism: \\ toward a new understanding of the philosophy \\ of Iamblichus
}

\author{
María Jesús Hermoso FÉLIX \\ Universidad Complutense de Madrid
}

Recibido: 15-07-2011

Aceptado: 17-01-2012

\section{Resumen}

La complejidad en el marco epistémico desarrollada en la filosofía de Jámblico no se deja apresar desde la polaridad que subyace a las categorías de racional e irracional. Tras la proyección de tales categorías el núcleo mismo de esta filosofía permanece incomprendido. En este artículo procuramos apuntar a la necesidad de una hermenéutica respetuosa con la filosofía neoplatónica que, desde sus propios postulados internos, despliegue modelos de comprensión que permitan la apertura al sentido y a la coherencia de este pensamiento. Un acercamiento serio a los textos pone en primer plano la importancia del método. Éste ha de acompañar la complejidad de su significación sin proyectar categorías ajenas que oculten sus núcleos de sentido básicos, intentando un adentramiento en sus líneas maestras. El despliegue de este camino arroja como resultado la puesta en evidencia de la precariedad de determinadas líneas exegéticas que tienden a ocultar, tras la proyección de parámetros conceptuales extraños, las claves básicas de acceso a este pensamiento.

Palabras Clave: Neoplatonismo, niveles de conocimiento, logos, razón.

\section{Abstract}

The complexity of the epistemological framework developed in the philosophy of Iamblichus does not allow to be captured from the polarity that underlies the 
categories of rational and irrational. After the projection of such categories, the core of this philosophy remains itself misunderstood. In this paper we intend to point to the need for a hermeneutic that respects the Neoplatonism that, from their own internal assumptions, display models that allow open understanding about the meaning and coherence of this thought. A serious approach to the texts foregrounds the importance of the method. This must accompany the complexity of its meaning without projecting beyond categories that hide their cores basic sense, attempting an inside their outlines. The deployment of this path indicates the result of the demonstration of the precariousness of certain exegetical lines that tend to hide behind the projection of conceptual parameters strangers, basic access key to this thought.

Keywords: Neoplatonism, knowledge levels, logos, reason.

\section{Introducción}

Desde los paradigmas vigentes de conocimiento, deudores en su mayoría de una comprensión tecno-científica, se hace muy difícil desplegar una hermenéutica que dé cuenta en lo esencial de la complejidad del modelo de conocimiento planteado por el Neoplatonismo. Esta incompatibilidad de paradigmas se encuentra a la base de la incomprensión del sentido básico de la cartografía epistémica que encontramos en esta corriente filosófica. Las categorías que se proyectan sobre ella empañan su coherencia interna e introducen contradicciones y paradojas que provienen directamente del lugar desde el que se acomete la exégesis. Este problema ha sido señalado por estudiosos del Neoplatonismo de la talla de J. Trouillard a propósito del pensamiento de Proclo: "Cette conception de la philosophie nous déconcerte parce que chez nous la philosophie tend à devenir un simple savoir ou un métier. Dans notre Occident le rationalisme et le primat de la technologie ont tellement imprégné notre mentalité qu'ils sont le plus souvent inconscients. D'où la difficulté d'entrer dans des pensées comme celle de Proclos, aussi longtemps que nous tentons de lui appliquer nos modèles d'intelligibilité"1. Superar este problema constituye la piedra de toque que abre la posibilidad de una intelección mínima de esta filosofia desde sus propios postulados internos. Urge atender a interpretaciones que desde la lógica inmanente a este modelo cognoscitivo sepan dar cuenta de su sentido, adentrándose en sus líneas maestras, abriéndose a su profundo calado y a su coherencia.

Si el marco teórico que plantea el Neoplatonismo en su conjunto escapa a las categorías de conocimiento vigentes hasta hacerse incomprensible desde las mismas ello se agudiza a partir de Jámblico. En su época, las especiales circunstancias

1 Trouillard, J.: La Mystagogie de Proclos, París : Les Belles Lettres, 1982, p. 12. 
históricas hacen que la filosofía sienta como una necesidad la articulación y la criba de las diferentes prácticas que se llevaban a cabo en la religión pagana. Era ésta la única oportunidad de supervivencia del mundo pagano ante la emergencia de una religión universalista como el cristianismo que amenazaba con ocupar la centralidad misma del ámbito socio-cultural del helenismo. La filosofía en esta época trata de llevar a cabo una exégesis de los rituales, otorgándoles dignidad epistémica, dando unidad y coherencia al paganismo.

Así, a la incomprensión de base que sufre esta filosofía se une la lejanía que siente la mentalidad dominante en nuestro tiempo hacia los focos de preocupación que se presentan a la filosofía neoplatónica en este momento concreto. Ello hace que estudiosos de la talla de Dodds se refieran al De Mysteriis como a un "manifiesto del irracionalismo, una afirmación de que el camino de la salvación no se encuentra en la razón sino en el ritual"2. La gravedad de esta afirmación adquiere enormes dimensiones si tenemos en cuenta que ha marcado la línea hermenéutica y de investigación de gran parte de los estudiosos que se han ocupado de Jámblico. Dar cuenta de la problemática asociada a esta afirmación es el primer paso para generar una hermenéutica ajustada a los textos que se haga cargo del sentido interno de los mismos. De ello depende que se haga visible el lugar que Jámblico ocupa en la historia de la filosofía y, con él, el de una línea de pensamiento que ha marcado profundamente gran parte de la filosofía occidental.

De cara a refutar la afirmación llevada a cabo por Dodds mostraremos los perfiles básicos de la teoría del conocimiento que encontramos en la obra de Jámblico, ubicándolos en los núcleos de la teoría del conocimiento platónica que desarrollan. Procuraremos, asimismo, mostrar que no hay ruptura sino continuidad con la hermenéutica neoplatónica precedente. A partir de los perfiles que presenta esta línea de pensamiento ha de hacerse evidente la imposibilidad de apresar su sentido en la polaridad que subyace a las categorías de racional/irracional, en el marco epistémico que conforman. Este marco deja incomprendidos los núcleos de sentido más íntimos de esta filosofía, aquellos que delimitan el telos del itinerario de conocimiento que propone, su modo mismo de desarrollo y de despliegue.

El campo semántico unido al concepto de razón hoy vigente no da cuenta de las diferentes potencias cognoscitivas que despliega este modelo epistémico. Ello introduce una incomprensión de partida que lastra la posibilidad de que emerja la cualidad y el carácter propio de modos de conocimiento que constituyen la culminación del saber en esta filosofía. La complejidad de los términos griegos que suelen traducirse por razón no se ve reflejada por esta traducción en la mayoría de los casos. Estos términos ven, así, reducida su significación, proyectándose sobre ellos categorías que les son ajenas. En este contexto toma cuerpo la importancia de aten-

2 Dodds, E. R.: The Greeks and the irracional, California: Universidad de California, 1951 (Trad. castellana de María Araujo, Los griegos y lo irracional, Madrid: Alianza, 1994, p. 270.) 
der a la significación de los términos griegos que vienen a traducirse por razón de cara a profundizar en el sentido interno de los mismos. Este estudio, en no pocas ocasiones, viene a poner en evidencia la precariedad en la correspondencia semántica que se establece demasiado a la ligera en la mayoría de las ocasiones ${ }^{3}$.

\section{Perfiles de la teoría del conocimiento de Jámblico}

La concepción del conocimiento sostenida por Jámblico si por algo se caracteriza es por su complejidad. Esta complejidad dota de espacio a diferentes niveles epistémicos que apuntan a diferentes niveles de comprensión y apertura a los fundamentos primeros de la realidad. Cada uno de estos niveles exigirá de mediaciones, de itinerarios, que faciliten su actualización en el alma del hombre. En este sentido, el conocimiento quedará determinado por su capacidad de transformación de la experiencia presente del alma. El sabio no es aquél capaz de almacenar información a través de la cual transformar la realidad sino, primordialmente, aquél que ha realizado en sí mismo una mirada penetrante hacia lo real. Todo otro nivel de conocimiento quedará al servicio de esta mirada, del modo en que se expresa en las diferentes facultades anímicas, del modo en que las integra, otorgándoles su plenitud y su equilibrio propio. Cada nivel de conocimiento es ubicado en una dinámica epistémica con su funcionalidad y su coherencia propias, donde no hay compartimentos estancos ni fracturas.

El corazón de esta comprensión del conocimiento se halla en la capacidad del alma para unirse al principio último de lo real: Tal será el origen y la culminación del camino epistémico. Esta culminación como tal trasciende el intelecto, reclamando del alma un modo de actividad supraintelectiva. Jámblico distinguirá en el pasaje de De Mysteriis 7.4.12 entre un modo de conocimiento intelectivo y un modo indecible superior y más simple. Estos modos de conocimiento son caracterizados como divinos en la medida en que conciernen a los principios originarios de la realidad y se llevan a cabo según un modo unitivo. En ellos la multiplicidad de lo real es acogida desde su sentido primero que atiende a la unidad misma que recorre el

\footnotetext{
${ }^{3}$ Urge desplegar un método hermenéutico capaz de hacerse cargo de los textos sin distorsionarlos. Un método que acompañe, en lo posible, la complejidad de su significación sin proyectar categorías ajenas que lo oculten en sus núcleos semánticos básicos. En este sentido, la atención previa a la significación de los términos a través de un estudio estructural de la semántica de los mismos constituye una vía sugerente de acceso al texto: Atender al contexto en el que aparecen así como a la relación que establecen con toda una constelación semántica de términos a los que están asociados en una relación estructural concreta. Este método de acercamiento al texto permite una comprensión más objetiva del mismo, capaz de poner en cuestión los modos de exégesis que proyectan categorías que le son ajenas. Cf. Calvo Martínez, T.: Léxico y filosofía en los presocráticos, en Logos. Anales del Seminario de Metafisica, 1971, vol. VI, p.7-23.
} 
alma del hombre "la unión simple que nos liga a los dioses siempre en acto a la manera del Uno" dirá Jámblico en De Mysteriis 1.3.104.

La cualidad de este saber se lleva a cumplimiento en la unión misma del que contempla y lo contemplado, señalada como telos del conocimiento ya desde el Timeo platónico donde se exhorta al hombre a la contemplación del Universo de modo que: "vuelva al que contempla semejante a lo contemplado de acuerdo con la naturaleza originaria" 5 . Este modo de saber trasciende el conocimiento que tiene lugar al nivel de lo humano en tanto ser particular que se mueve en el mundo de la multiplicidad como un ser más entre otros. Tipo de conocimiento, este último, que se caracteriza por estar asentado en procesos de referencia externa que reclaman de la existencia de la dualidad sujeto-objeto como su condición misma de posibilidad.

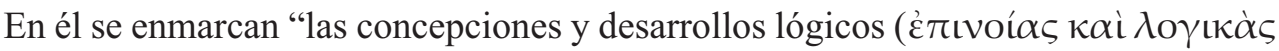

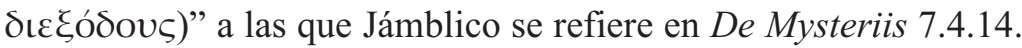

La dinámica propia de despliegue del proceso epistémico pasará por la necesidad de trascender los modos de conocimiento que se asientan en la multiplicidad de cara a facilitar la irrupción del modo unitivo de actividad que corresponde a las potencias superiores del alma. Ello no significa, sin embargo, que esta filosofía rechace este modo de conocimiento. Su correcto ordenamiento se considera fundamental como condición previa al acceso a modos superiores de saber: Si este ámbito cognoscitivo no está bien ordenado actuará a la manera de un espejismo, ocultando la actividad unitiva en la que el alma se fundamenta. No hay en el alma compartimentos estancos cada uno de los cuales desarrolle su actividad de modo aislado. Ésta constituye un todo articulado y bien trabado donde cada facultad moviliza a todas las demás. Se trata, por tanto, de equilibrar cada una de las potencias de manera que ocupe el lugar que le es propio, permitiendo y facilitando la plenitud de todas las demás.

De este modo, es de vital importancia que el ámbito lógico y del razonamiento esté bien orientado de cara a ser trascendido en modos más unitivos de comprensión. Esta filosofía no propone descartar ningún modo de conocimiento como inútil sino que procura el equilibrio de todas las potencias, abriendo la puerta a la cul-

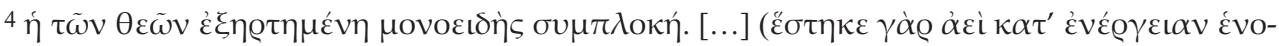
$\varepsilon เ \delta \tilde{\omega} \varsigma)$. En este punto es importante tomar en cuenta la comprensión de lo divino que encontramos en la filosofía de Jámblico. Los dioses no son concebidos al modo de entes separados que se ubicarían en algún lugar lejano con el que el hombre podría establecer algún tipo de conexión. Por el contrario, lo divino constituye el principio causal mismo de lo real. Los perfiles de la realidad, la infinidad de las formas del mundo son conformadas en la inmanencia trascendente de lo inteligible (Cf. entre otros lugares, Myst. 1.8.70 ss.). Esta unidad creadora recorre el alma del hombre ligándola en su núcleo mismo al sentido primero de la realidad.

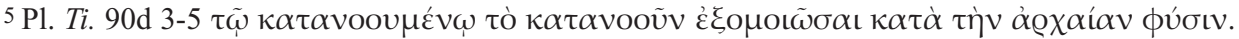
En relación a este pasaje platónico es interesante tomar en cuenta el estudio que lleva a cabo Festugière en La révélation d'Hermes Trismégiste, París: Les Belles Lettres, 2006, p. 133 ss.
} 
minación del camino epistémico en la unión misma al principio originario de lo real. En este sentido, apunta Jámbico en De Mysteriis 2.11.16 a que "la unión activa no se genera nunca sin el conocimiento, si bien éste no se identifica con aquella".

El conocimiento que tiene lugar al nivel predicativo y del razonamiento, que corresponde a lo que hoy comúnmente entendemos por razón, no es negado en modo alguno, sino ubicado en un lugar concreto, a saber, aquél que compete al ámbito de lo humano en tanto ser que se mueve en el ámbito fenoménico. Lo que Jámblico viene a poner de manifiesto es que el ámbito predicativo y del razonamiento así como las facultades y potencias del alma relacionadas con esta capacidad no colapsan la capacidad cognoscitiva del alma ni son la cumbre del camino epistémico.

El alma humana guarda en sí potencias cognoscitivas más altas desde las que se abre la posibilidad de un grado de comprensión más profundo de la realidad. Aquel grado de comprensión que se alcanza por semejanza con los principios mismos que rigen lo real y constituyen su fondo primordial. Este modo de comprensión unitivo trasciende el ámbito del razonamiento. Toda vez que el mismo nivel del razonamiento se ve ordenado y plenificado desde una comprensión que lo trasciende por su misma cualidad unitiva. Éste ha de tornarse, entonces, reflejo de una comprensión más alta en el nivel que le es propio, propiciando en este ámbito el camino que ha de llevar al alma a la culminación del conocimiento más allá del nivel dual de la predicación y el razonamiento.

Ello no significa, sin embargo, que este conocimiento unitivo del que es capaz el alma sea irracional. Bien al contrario, constituye la fuente de las potencias cognoscitivas del alma que atañen a la multiplicidad, trascendiéndolas en un grado más profundo de comprensión. En esta culminación unitiva cada una de las facultades inferiores de conocimiento encuentra su orden, su plenificación y su sentido en el nivel que le es propio.

\section{Ubicación en el contexto del pensamiento platónico}

Esta reflexión constituye, por otro lado, uno de los núcleos de preocupación teórica de toda la tradición platónica. En su teoría del conocimiento Jámblico se ubica en una línea de pensamiento que, remontando hasta Platón, comienza a elaborarse en el platonismo medio en la figura de Alcínoo y es madurada en el pensamiento de Plotino. Nos referimos a la cartografía del itinerario epistémico que resulta de la lectura neoplatónica de República 509b.9 y de República 517b.1-c.6. En el primer

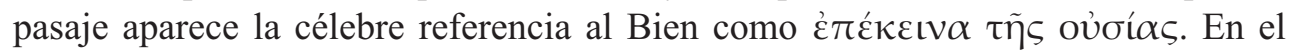
segundo pasaje se llevan a cabo dos afirmaciones simultáneas, de un lado se afirma que el Bien es susceptible de contemplación y conocimiento, de otro lado se le señala como la fuente de la verdad y del intelecto: 
Lo que dentro de lo cognoscible se ve al final, y con dificultad es la idea del Bien. Una vez percibida ha de concluirse que es la causa de todo lo justo y lo bello que hay en todas las cosas, que en el ámbito visible ha engendrado la luz y al señor de ésta y que en el ámbito inteligible es señora y productora de la verdad y del intelecto ${ }^{6}$.

Si a esto añadimos la toma en consideración del presupuesto que subyace a la obra platónica de que lo semejante es conocido por lo semejante ${ }^{7}$ tenemos presentes las claves necesarias de las que se deriva la hermenéutica que da lugar al modo en que se concibe la dinámica epistémica en el Neoplatonismo:

1. En República 509b.9 el Bien en tanto lo que está más allá de la esencia se conforma como lo indecible, lo inefable que trasciende la configuración particular de los seres, estando, al mismo tiempo, presente en ellos como su causa misma

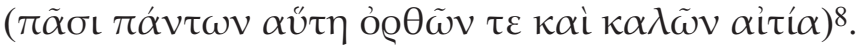

2. Asimismo, el Bien como principio inefable es la fuente que da lugar al intelecto ( generadora.

3. El Bien es señalado simultáneamente como elemento susceptible de ser cono-

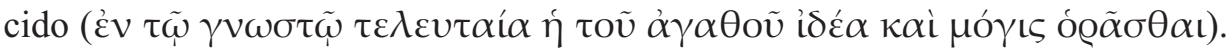

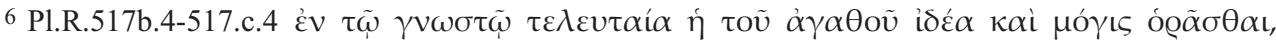

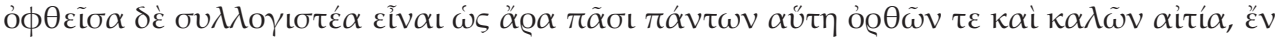

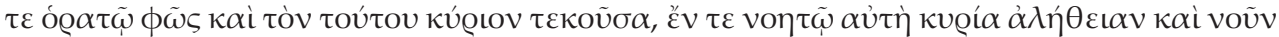
$\tau \alpha \varrho \alpha \sigma \chi 0 \mu \varepsilon ́ v \eta$. La traducción de los textos griegos corresponde, con alguna pequeña variación, a la versión castellana referida, en cada caso, en la bibliografía.

7 Muchos son los lugares de la obra platónica donde encontramos expuesto el postulado epistemológico de que lo semejante es conocido por lo semejante, entre ellos Protágoras 337d.1, Gorgias 510b.4, República 490b.4 o Leyes 716c.2. Es este un elemento que encontramos desde los tiempos más tempranos de la filosofía griega y sobre el que han de girar las concepciones del conocimiento del Neoplatonismo, siendo una tesis central en el pensamiento de Plotino, de Jámblico o de Proclo. Cf. Iambl. Protr. 109.12 y De Myst. 1.15.24.

${ }^{8}$ En este punto es importante remarcar la vertiente inmanente de la noción platónica del Bien bajo cuya luz ha de ser siempre acometida la hermeneútica de los textos que hacen hincapié en su trascendencia. Es éste uno de los grandes retos hermeneúticos a los que nos enfrenta la obra platónica. De él tratan de hacerse cargo hoy día estudiosos del platonismo como Ross que en su Plato's Theory of Ideas (Traducción castellana de Díez Arias, J.L: Teoría de las ideas de Platón, Madrid: Cátedra, 1997, p. 270-271) lleva a cabo un listado comparativo de los lugares de la obra platónica donde se marca la inmanencia de las ideas y de aquellos en los que la trascendencia es puesta en un primer plano. Textos como el de Fedón 100d.4 deben ser colocados en un lugar central de nuestra reflexión: "Que ninguna otra cosa la hace bella a no ser la presencia o la comunicación o cualquier otro que sea el modo en que

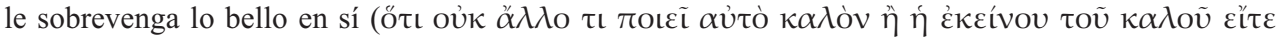

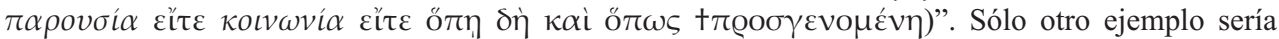
Gorgias 506d: "bueno, aquello por cuya presencia somos buenos ( $\dot{\alpha} \gamma \alpha \theta$ òv $\delta \dot{\varepsilon}$ oũ $\pi \alpha \rho o ́ v \tau o \varsigma ~ \alpha ̉ \gamma \alpha \theta o i ́$ $\dot{\varepsilon} \sigma \mu \varepsilon v) "$
} 
Estos aspectos, tomados conjuntamente, reclaman una noción del alma abierta a la capacidad de trascenderse del intelecto para arribar a la contemplación del Bien, en la medida en que éste se configura como principio inefable, fuente del intelecto. Ha de haber en el alma un lugar semejante al Bien susceptible de allegarse a su conocimiento y de tomar contacto con él. Tal lugar será lo inefable del alma, el ámbito donde ésta es capaz de trascender todo conocimiento que proceda de las potencias implicadas en la multiplicidad. En este proceso de acercamiento al Bien y de asimilación con él, el intelecto mismo se ve trascendido, abriéndose a la fuente de la que surge.

La reflexión sobre el modo en que el alma se abre al principio inefable que constituye lo real a través de lo que en ella hay de semejante a éste será una constante del pensamiento neoplatónico. Este lugar de la semejanza, trascendiendo el intelecto, es situado en la cumbre misma del proceso cognoscitivo, concebido éste como un proceso anagógico que culmina en la unión al principio fundante de lo real y del alma. La cartografía de la culminación de éste proceso así como los términos con los que queda referido varían. Es en este ámbito, más que en ningún otro, donde el lenguaje mismo se torna simbólico, aludiendo a lo que necesariamente le sobrepasa. Numerosos son los textos que hemos de encontrar en este sentido en la obra plotiniana. Uno de ellos nos servirá por el momento como muestra, se trata de En. V 5, 8, 14:

Aquél, por su parte, no vino como se podía esperar, sino que llegó sin llegar. Porque fue visto como quien no vino, sino que está presente antes que todos, aún antes de llegar el intelecto; el que llegó es el intelecto, como también es el intelecto el que se ausenta, porque no sabe dónde debe permanecer ni dónde está Aquél, esto es, en ninguna parte. Y si le fuera posible al intelecto mismo no permanecer en ninguna parte, no localmente -éste no está tampoco en lugar alguno- sino absolutamente en ninguna parte, estaría siempre mirando a Aquél. Aunque no mirándolo sino siendo con El una sola cosa, y no dos. Pero de hecho aunque es intelecto, lo mira, cuando lo mira, con aquello de sí mismo que no es intelecto. Lo realmente sorprendente es cómo Aquel, sin haber venido, está presente, y cómo, sin estar en ninguna parte, no hay ninguna parte donde no esté. Esto así a primera vista, es en sí sorprendente; pero para un entendido sería sorprendente si fuera lo contrario, mejor dicho, ni siquiera cabría la posibilidad de sorprenderse ${ }^{9}$.

\footnotetext{
9 Plot. En. V.5.8.13-17.

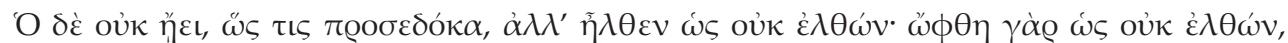

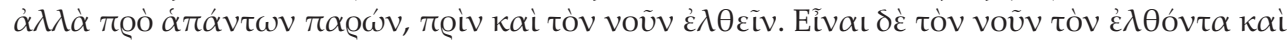

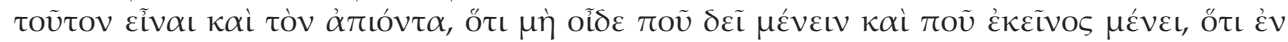

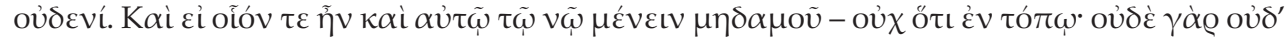

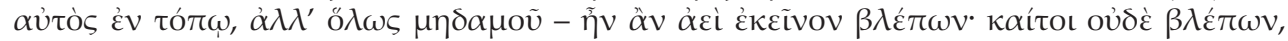

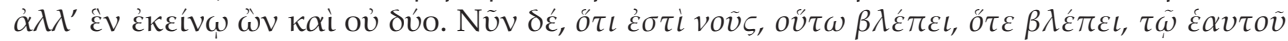

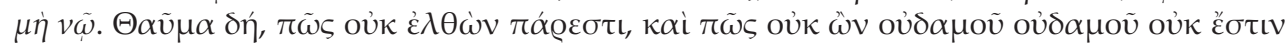

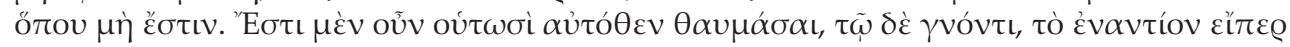

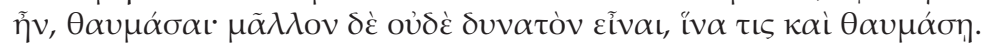


En este texto quedan expresadas algunas de las coordenadas centrales en las que Jámblico ubica su comprensión de lo simbólico y la noción del alma que se desarrolla en articulación interna con ella. La naturaleza misma del primer principio se muestra como esencialmente paradójica: "Cómo Aquél sin haber venido está presente, y cómo, sin estar en ninguna parte, no hay ninguna parte donde no esté $(\pi \tilde{\omega} \varsigma$

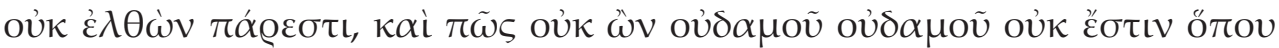

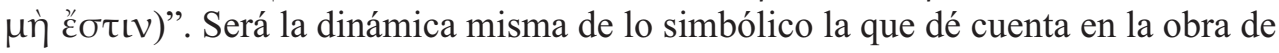
Jámblico de esta articulación del primer principio en el modo de una inmanencia trascendente. Este se refiere al modo de la presencia del principio originario que rige lo real de la siguiente manera: "como la nada, por decirlo así, se encuentra lo que rige en lo regido"10. En esta compleja constitución de la realidad, el fundamento inefable de la misma se manifiesta en ella en el modo de no manifiesto que le es propio. El principio originario, siendo la fuente del intelecto, no por ello se sitúa en un más allá inalcanzable para el alma, pues, no estando en un lugar, el modo

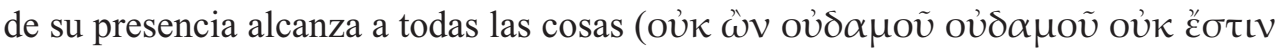

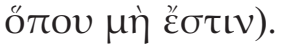

La cualidad de la presencia del primer principio como raíz fundante de lo real y del alma ha de marcar la comprensión del proceso del conocimiento como un proceso de unificación. El intelecto en la medida en que se asimila al modo de la presencia del primer principio se hace uno con él. Ahora bien, esto es sólo posible desde la raíz misma que le constituye pero al mismo tiempo le trasciende en tanto que intelecto. De ahí que Plotino apunte a que el contacto con el principio último

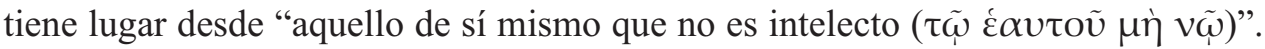

También Proclo, en numerosos lugares de su obra, se refiere a la cumbre del proceso cognoscitivo como un trascenderse del propio intelecto. La capacidad del alma de unificarse con el principio último de toda realidad y fuente del intelecto recibe varias denominaciones, la más común será la de flor del intelecto:

Por doquier lo semejante tiene natural disposición a unirse a lo semejante, y todo conocimiento por semejanza liga lo que piensa a lo pensado, lo que siente a lo sensible, la facultad dianoética a lo racional, y lo que intelige a lo inteligible, y, consiguientemente, también la flor del intelecto a lo que es anterior al intelecto. Porque como en los otros campos lo más eminente no es el intelecto, sino la causa que está sobre el intelecto. Así también entre las almas la primera forma de actividad no es intelectiva sino más divina que el intelecto ${ }^{11}$.

\footnotetext{
10 Iambl. Myst. I 957

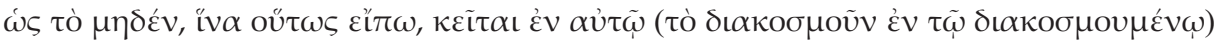

11 Procl. Phil. Chal. IV 5-14

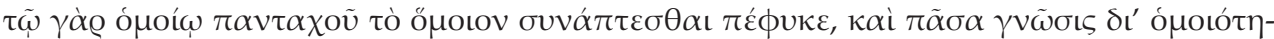

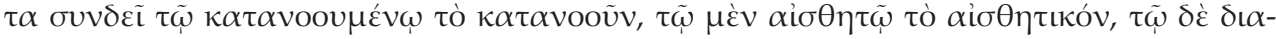

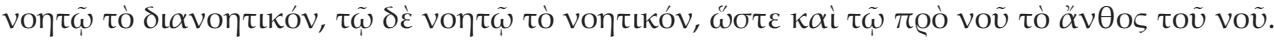


Este principio del alma que es capaz de trascender el intelecto y de unirse al

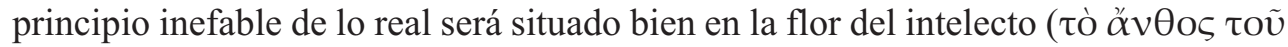
voṽ), como lugar donde éste se trasciende a sí mismo, bien en la existencia suprema del alma ( $\tilde{\eta} \alpha \check{\kappa} \varrho \alpha \tilde{u} \pi \alpha \varrho \xi ı \varsigma \tau \tilde{\eta} \varsigma \psi v \chi \tilde{\eta} \varsigma$ ), la unidad suprema de todas sus potencias $^{12}$. En todos los casos se expresa la disimetría del intelecto y del principio supremo que constituye su fundamento último. Junto con ello se apunta a que en el alma hay un elemento semejante a éste principio, capaz de unirse a él, trascendiendo al intelecto, y culminando con ello el proceso epistémico.

\section{La crítica de Dodds y el concepto de razón}

Como se puede observar en los textos la reflexión sobre el modo en que el alma se une al principio último es ya un tema clásico que arranca del propio Platón. La cualidad de esta unión como trascendente al intelecto, en la medida en que el principio último es la fuente que lo sobrepasa, queda ya perfilada desde los inicios del platonismo. Si bien esta visión es desarrollada y madurada a partir de Plotino. En este punto Jámblico en sus reflexiones sobre el alma y su modo de conocimiento no hace sino insertarse en esta línea. Sin embargo, debido a los motivos de reflexión de los que se hace cargo, su pensamiento ha sido objeto de múltiples malentedidos por parte de la corriente exegética mayoritaria. Tal es el caso de Dodds que, como hemos apuntado al comienzo, en su ya consagrada obra Los griegos y lo irracional señala el De Mysteriis como: "Un manifiesto del irracionalismo, una afirmación de que el camino de la salvación no se encuentra en la razón sino en el ritual"13. Según esta interpretación Jámblico habría introducido una vía de contaminación de la filosofía a través de las prácticas asociadas al ámbito mistérico.

Como venimos viendo, un acercamiento básico a los parámetros en los que se mueve su teoría del conocimiento muestra la imposibilidad de atender al sentido interno y a la coherencia de esta filosofía a través de este tipo de exégesis. Es necesaria una lectura diferente de su obra que dé cuenta en profundidad de este desarrollo de la filosofía neoplatónica que ha de marcar todo el Neoplatonismo posterior y gran parte de la filosofía de Occidente. La obra de Jámblico ha de ser enmarcada y vista bajo la luz del camino epistémico que traza el pensamiento de Plotino para, a partir de aquí, emprender una exégesis del desarrollo y las novedades que Jámblico introduce. En este punto las especiales circunstancias históricas que le rodean tienen un papel a todas luces relevante.

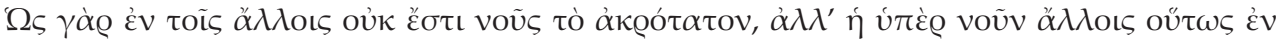

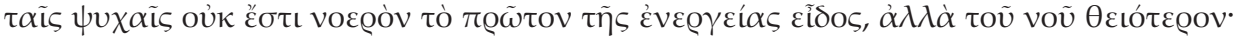

12 Cf. Ibid. IV 1. Asimismo, cf. In Alc. 246.118-248.3 e In Ti. 254.29.

13 Dodds, op. cit. 
Finalmente, nos acercaremos a la problemática asociada a esta línea de interpretación desde el ángulo propiamente terminológico. Desde este punto de vista, de cara indagar en la validez de la afirmación llevada a cabo por Dodds, ha de tomarse en cuenta la complejidad semántica de los términos griegos que se traducen desde el campo significativo que en las lenguas modernas asociamos a la razón. Es importante partir de un análisis de estos términos para ver si afirmaciones como la que nos ocupa parten de elementos presentes en los textos mismos o son proyectadas desde parámetros conceptuales ajenos. Cuando se trata de esto último nos encontramos ante la situación de que el sentido de la filosofía que se pretende interpretar permanece velado, oculto tras reflexiones que no hablan sino del marco exegético de salida, de sus carencias, de su dificultad para acceder a la coherencia de determinado marco teórico. Este es uno de los principales obstáculos a los que se enfrenta la exégesis de la filosofía neoplatónica, especialmente a partir de Jámblico: La matriz misma de la cual emanan sus núcleos de sentido básicos ha llegado a percibirse con una gran distancia desde determinados lugares comunes que han devenido inconscientes en la mayoría de los casos. Estos núcleos de sentido quedan velados por proyecciones de marcos conceptuales ajenos que imposibilitan el acceso a las claves de comprensión de esta filosofía.

Abrir un espacio a la comprensión de este pensamiento requiere indagar en profundidad en un vasto campo de estudio: el sentido mismo de la filosofía, el valor epistémico de la belleza y su vinculación con el ritual, estos y otros temas han de ser tratados con detenimiento. Por el momento, en el presente estudio, nos hemos centrado en uno de los aspectos que nos parece decisivo a la hora de abrir un ámbito serio de comprensión de este marco teórico: la imposibilidad de dar cuenta del mismo desde un marco conceptual que se mueva en los parámetros de racional-irracional. Esta imposibilidad se pone, asimismo, de relieve si atendemos a un perfil mínimo del sentido de los términos que suelen traducirse por razón en nuestro castellano actual. Normalmente son dos los términos griegos que vienen a traducirse

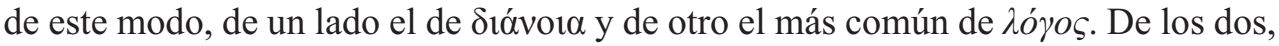
el primero es el que mejor refleja el concepto de razón hoy vigente en tanto referido al ámbito predicativo y del razonamiento. Éste es el término que elige Platón en la República para referirse a la facultad del alma que se ocupa de la "geometría y de las ciencias afines a ella"14. No hemos de olvidar que la razón, en este sentido, se ubica ya desde la República platónica en un ámbito reducido de conocimiento que en ningún caso dará cuenta de la capacidad del alma para unirse al principio último de lo real15. En este sentido, al señalar el De Mysteriis de Jámblico como irracional tendríamos que implicar en tal afirmación a la historia entera del plato-

\footnotetext{
14 Pl. R. 511b. 1

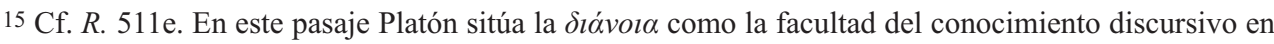
un ámbito intermedio del camino epistémico y en ningún caso como la culminación de dicho proceso.
} 
nismo. Ningún pensador platónico, siguiendo en esto al propio Platón, ha visto la salvación del alma en la razón así entendida.

En cuanto al término $\lambda$ ó $\gamma$ s, una de sus cualidades más características es precisamente su dinamicidad y su complejidad. Pues logos se refiere al ámbito del razonamiento y del desarrollo predicativo, pero, a su vez, éste es reflejo en el ámbito lógico de un desarrollo más originario propio del logos. Allá donde hay logos hay un desenvolverse, un desplegarse en la multiplicidad de aquello que la sobrepasa. En cuanto facultad propiamente mediadora, en no pocas ocasiones su sentido viene asociado al de intelecto, si bien como facultad del alma capaz de allegarse a él y desplegarlo. En este sentido, Plotino lo asocia al desplegarse del inteligible, siendo el que lo traslada de la facultad intelectiva a la imaginativa ${ }^{16}$. En este caso se marca su condición de mediación, su dinamicidad propia capaz de servir de puente entre la facultad intelectiva y la imaginativa del alma.

En el logos se encuentra la posibilidad misma de desarrollo de lo que se halla en estado de indivisión, de la manifestación a todos los niveles de lo que trasciende el nivel propio de lo sensible. Esta potencia creadora del logos en conexión con el intelecto viene a caracterizarse como una vertiente propiamente ontológica del mismo. Éste despliega lo inteligible en las razones creativas de todas las cosas.

Plotino diferencia claramente esta vertiente, que hemos llamado ontológica, de la vertiente propiamente lógico-predicativa del logos, aquella que tiene que ver con la capacidad de generar razonamientos, que se asientan en un proceso de referencia externa de un sujeto a un objeto. A este respecto leemos en En. IV 3.18.2-13:

El razonar se hace presente en el alma en este mundo cuando se halla desconcertada, llena de preocupaciones y más debilitada. [...] El razonar hay que entenderlo de esta manera porque si uno entiende por razonar ${ }^{17}$ esa disposición que, dimanando perennemente del intelecto, está presente en las almas y que es una actividad estable y una espe-

16 Cf. En. IV 330 5-11: “Tal vez lo que la imaginación acoge en su interior es el logos que acompaña al inteligible. Es que el inteligible es indiviso y, cuando aún no ha salido fuera, por sí decirlo, no nos percatamos de que está dentro. Más el logos, desplegando el inteligible y trasladándolo de la facul-

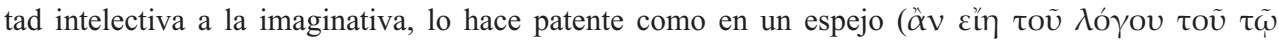

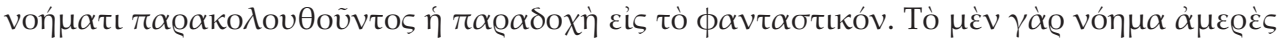

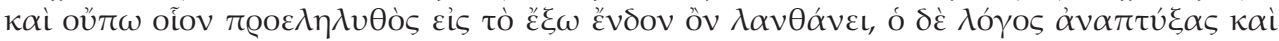

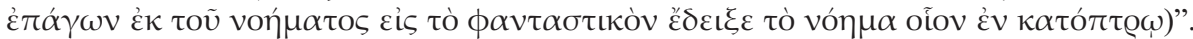

17 Este sentido que Plotino atribuye a la razón escapa al modo en que actualmente comprendemos la razón y sus funciones, ligadas siempre al ámbito predicativo y del razonamiento. Hasta el punto de que un razonar no referido al ámbito de la predicación nos es ajeno. Si bien el castellano en su potencialidad semántica es capaz de dar de sí este significado tan íntimo al logos griego. Se trata de un razonar en el sentido de generar las razones mismas que miden y dan sentido esencial a lo real. Este razonar, este conformar las medidas de los seres en vinculación con lo inteligible, es antepredicativo, pertenece al logos como principio creativo que da de si la planta misma que conforma esencialmente a los seres. 
cie de reflejo del intelecto cabe decir que las almas se sirven del razonar aún en el mundo de allá18.

Jámblico se incardina en esta línea apuntando a una dimensión ontológica del logos que abraza las formas de los seres. Las estructuras creativas mismas de lo real se contienen en esta dimensión formativa del logos. Junto a esta dimensión ontológica se hace referencia a una perspectiva propiamente lógico-predicativa, vinculada al proceso de la significación. "La divinidad imprimió <en el hombre $>$ el sistema del logos pleno ( todas las formas de los seres y la significación de los nombres y los verbos", leemos en Protréptico 19.19-20.

Proclo se referirá a esta dimensión ontológica del logos en su Comentario al Timeo I 248.1-6 con las siguientes palabras:

El logos circula en torno a lo inteligible y ejerce su actividad y su movimiento como en torno a un centro, en estas condiciones contempla lo inteligible, conociendo la intelección lo inteligible de manera no discursiva e indivisible, evolucionando el logos en círculo en torno de la esencia y desarrollando la naturaleza sustancial de todas las cosas que se encuentra unificada en lo inteligible19.

En líneas anteriores al presente texto 20 encontramos sistematizados los sentidos del logos en la obra platónica. En esta sistematización Proclo da cuenta de la dinamicidad que marca la significación del término logos. Dos sentidos son señalados, cada uno de los cuales se bifurca a su vez en otras tantas diferenciaciones. El primero de ellos apunta a la dimensión propiamente lingüística del logos: "la enunciación de lo que se piensa, la exposición de los elementos que componen el objeto, la frase que indica las características distintivas de un objeto dado en relación a otros"21. El segundo es el que apunta al logos en tanto dynamis del alma. La complejidad en la significación no queda aquí colapsada sino que el logos se predica de cada uno de los niveles cognoscitivos del alma, distinguiéndose entre logos opina-

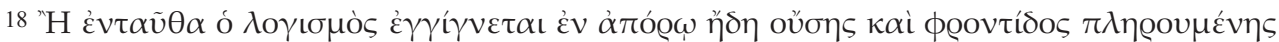

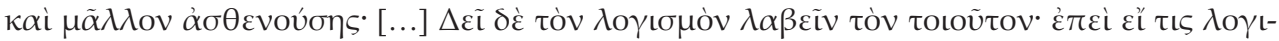

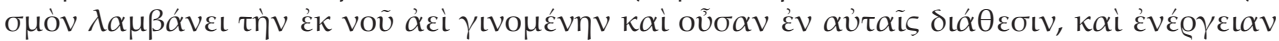

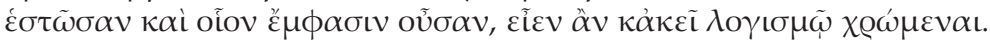

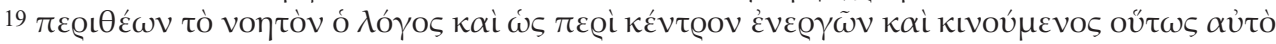

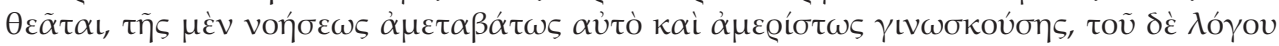

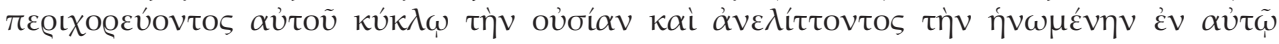

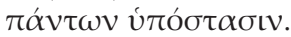

20 Ibid. 246.10 ss.

21 De ellos dirá Proclo que, por implicar composición y división, no son aptos para la aprehensión del

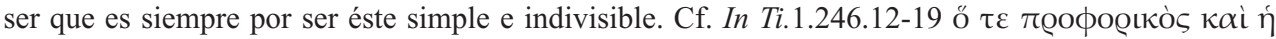

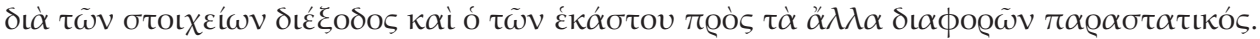




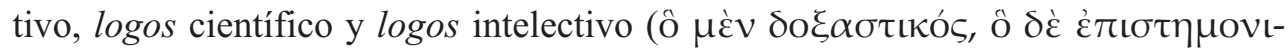

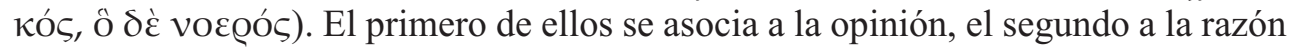

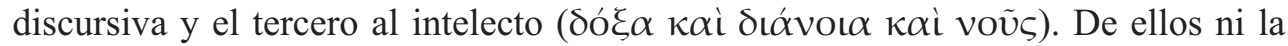
opinión ni la razón discursiva son aptas para la contemplación de lo inteligible. De la razón discursiva se dice lo siguiente:

Tampoco la razón discursiva, en la medida en que va hacia lo múltiple y la división, es capaz de remontar hasta el intelecto, al contrario, puesto que presenta una sucesión de razonamientos diferentes, se aleja de la indivisión del intelecto 22 .

Proclo traduce aquí una teoría que se constituye en lugar común para la gran mayoría de los intérpretes clásicos de Platón. El pensamiento discursivo, por su condición misma, no alcanza la visión directa de lo inteligible. La necesidad misma de trascender este ámbito 23 para ascender en el camino epistémico es una de las claves de la filosofía platónica, como se pone de manifiesto en los libros centrales de la República. Será el logos intelectivo el que se ligue al intelecto por su afinidad con

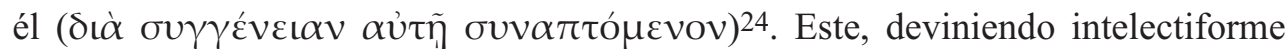

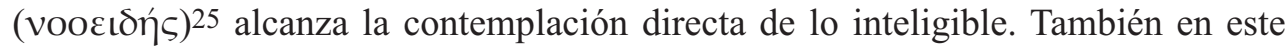
sentido, el más alto de los que aquí le adjudica Proclo, se pone de manifiesto la condición de desarrollo que acompaña siempre al logos. En este caso tal condición va ligada a la capacidad creativa del logos en la medida en que desarrolla lo que en lo inteligible se encuentra en estado de unificación.

El término logos se caracteriza por su dinamicidad propia y por la complejidad de su significación. Es quizá la potencia epistémica más íntima del alma, aquella que la acompaña en cada una de sus disposiciones cognoscitivas. Poco a poco el término razón ha ido perdiendo esta dinamicidad para fijar su significado en lo que en la filosofía neoplatónica vendría a designar la vertiente exclusivamente lógico-predicativa del logos. En nuestro lenguaje cotidiano este término ha perdido toda su connotación dinámica, de modo que no puede ya reflejar esa otra vertiente que es inseparable del logos en la tradición neoplatónica. El concepto de razón actual es

\footnotetext{
22 In Ti. $1.246 .26-28$

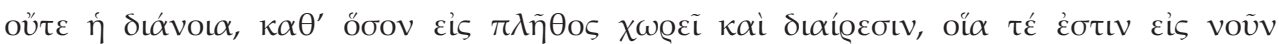

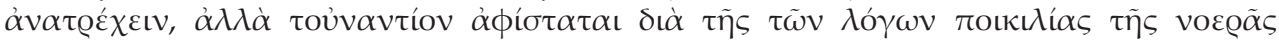
$\alpha \dot{\alpha} \mu \varepsilon \varepsilon \varepsilon^{\alpha} \alpha \varsigma^{\circ}$

23 Por trascender no debe aquí entenderse un mero dejar de lado, sino más bien aquello que en griego

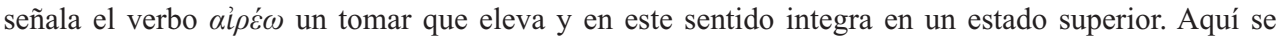
encuentra la posibilidad misma del carácter pedagógico de la razón, en la medida en que el buen ordenamiento del pensamiento transmite al alma una información que lo transciende. Toma aquí todo su sentido el término platónico de hipótesis como aquello que, mediando, debe ser trascendido en un conocimiento superior.

24 Cf. In Ti. 1.246 .31

25 Cf. Ibid. 1.247.25
} 
ajeno a esa disposición contemplativa del alma que trasciende lo predicativo para conformarse en un despliegue de lo inteligible en las razones creativas de todas las cosas. Hasta el punto de que este ámbito, tan íntimo al logos griego, vendría a quedar del lado de lo irracional para las categorías vigentes de conocimiento, puesto que esta potencia creadora del alma en conexión con el intelecto trasciende el ámbito lógico-predicativo que hoy en día se identifica con la razón.

Siendo esto así, no puede extrañarnos la incapacidad de las categorías de conocimiento vigentes en nuestra época para acompañar en su exégesis la complejidad del marco epistémico desarrollado por el Neoplatonismo. Máxime cuando la capacidad cognoscitiva del alma no se agota en esta contemplación del intelecto que despliega las estructuras creativas mismas de la realidad, sino que viene a culminarse en la unión cumplida al principio originario de lo real. Esta unión del alma al principio originario, como tal, trasciende el intelecto. Toda vez que se conforma en la fuente que lo posibilita, constituyendo la raíz misma desde la que el alma despliega cada una de sus potencias cognoscitivas.

En este contexto podemos observar que la complejidad de la cartografía del alma y del camino cognoscitivo perfilada ya por Platón y desarrollada por el Neoplatonismo no se deja apresar en la afirmación de Dodds. Ningún platónico ha visto en la razón, entendida en su sentido actual, la piedra de toque de la salvación del alma. Y ello no significa en ningún caso que la $\sigma \omega \tau \eta \rho i \alpha ~ \tau \tilde{\eta} \varsigma \psi v \chi \tilde{\eta} \varsigma$ se haya ubicado del lado de lo irracional. En la medida en la que la razón no es la potencia superior del alma no puede darse cuenta de la complejidad de las facultades cognoscitivas desde la estrecha dicotomía racional-irracional. El correlato aparentemente claro entre razón e irracionalidad en su significado común es incapaz de dar cuenta de los parámetros epistémicos involucrados en la teoría Neoplatónica del conocimiento ya desde Plotino. Este tandem, que tan profundamente ha marcado la exégesis moderna de los textos, ha de ser cuestionado para poder acceder a una compresión que dé cuenta del pensamiento neoplatónico sin vulgarizarlo o malentenderlo. A este respecto es paradigmática la afirmación llevada a cabo por Heidegger en Hacia la pregunta del ser 388:

La ratio hunde sin vacilar todo lo no conforme a ella en el supuesto, y además por ella misma delimitado, pantano de lo irracional. La razón y su representar son solo una clase del pensar (...). El que su dominio se erija como racionalización de todos los órdenes, como normalización, como nivelación en el curso del desarrollo del nihilismo europeo, da tanto que pensar como sus correspondientes intentos de huída hacia lo irracional. Lo más grave de todo es, sin embargo, el proceso del que el racionalismo y el irracionalismo se involucren por igual en un negocio de intercambio, del que no sólo ya no saben cómo salir, sino que tampoco quieren ya salir26.

26 Heidegger, M.: Hacia la pregunta del Ser. Traducción castellana de Molinonuevo J.L., Barcelona: Paidós, 1994. 
El proceso aquí señalado por Heidegger ha marcado enormemente la exégesis de parte de los estudiosos del Neoplatonismo. Es urgente salir de estas categorías para ver al Neoplatonismo desde sí mismo o al menos desde categorías que den cuenta de él de una manera más completa. En el caso concreto de Jámblico, más que en ningún otro, se dirime la posibilidad misma de la inteligibilidad de su lugar y su importancia en la historia de la filosofía occidental. Mucho nos jugamos en el intento de superación de un marco teórico que no puede dar cuenta de la complejidad y de la enorme riqueza de los núcleos de sentido que se proponen a la reflexión en este momento. Máxime cuando tras la proyección de este marco teórico, que deviene inconsciente en la mayoría de las ocasiones, se halla la imposibilidad misma de la apertura de un espacio de comprensión a cuestiones de tan vital importancia como el carácter y la naturaleza de ámbitos de conocimiento que han sostenido el corazón de corrientes de pensamiento fundamentales de nuestra historia.

\section{Bibliografía básica}

\section{Autores antiguos}

JÁmBlico. Jamblique. Les Mystères d'Égypte, ed. y trad. E. Des Places, París : Les Belles Lettres, 1966.

Jámblico, Sobre los Misterios Egipcios, trad. E. Ramos Jurado, Madrid: Gredos, 1997.

Jamblique, Protreptique, ed. y trad. E. Des Places, París : Les Belles Lettres, 1986. Jámblico. Protréptico, trad. M. Pierago, Madrid: Gredos, 2003.

Jamblique, Vie de Pythagore, trad. L. Brisson, A Ph. Segonds, París : Les Belles Lettres, 1996.

Jámblico, Vida Pitagórica, trad. M. Pierago, Madrid: Gredos, 2003.

OrÁculos Caldeos. Oracles Chaldaïques avec un choix de commentaires anciens, introd., texto griego, trad. y notas de E. des Places, París : Les Belles Lettres, 1971.

Oráculos Caldeos con una selección de testimonios de Proclo, Pselo y M. Itálico, introd., trad. y notas de F. García Bazán, Madrid: Gredos, 1991.

Platón. Platonis Opera, I-V, ed. J. Burnet, Oxford: Clarendon Press, 1961.

Platón. República, introd., trad. y notas de C. Eggers, Madrid: Gredos, 1986.

Fedón, Banquete, Fedro, introd., trad. y notas de C. Carcía Gual, M. Martínez y E. Lledó, Madrid: Gredos, 1986.

Plotino. Enéadas I-VI, 3 vols. Introd., trad. y notas de J. Igal, Madrid: Gredos, 1982-1998.

Proclo. Théologie platonicienne, introd., trad. y notas de Saffrey H. D. y Westerink L.G., 6 vols., París : Les Belles Lettres, 1968-1981. 
Commentaire sur la République, trad. y notas de Festugière A. J., 3 vols., París : Vrin, 2005.

Commentaire sur le Timée, trad. y notas de Festugière A.J., 3 vols., París : Vrin, 1966.

\section{Estudios modernos}

BeIerwaltes, W.: Denken des Einen. Studien zum Neuplatonismus und dessen Wirkungsgeschichte, Frankfurt: Vittorio Klostermann, 1985. (Trad. Italiana de Gatti L.: Pensare l'Uno. Studi sulla filosofia neoplatonica e sulla storia dei suoi influssi, Milán: Vita e pensiero, 1991).

BRÉHIER, É.: Études de philosophie antique, París : P.U.F., 1955.

BRÉHIER, É.: La philosophie de Plotin, París : Vrin, 1999.

Calvo Martínez, T.: Léxico y filosofía en los Presocráticos, en Logos, 1971, vol. VI, p. 8-23.

DodDs, E. R.: The greeks and the irracional, Berkeley: Univ. of California Press, 1973 (Trad. española de Araujo M.: Los griegos y lo irracional, Madrid: Alianza, 1981).

Festugière, A. J.: La Révélation d'Hermès Trismégiste, París: Les Belles Lettres, 1949-1954 (Parte III: Les doctrines de l'âme, suivi de Jamblique, Traité de l'âme, París, 1953).

Festugière, A. J.: Contemplation et vie contemplative selon Platon, París: Vrin, 1967.

Festugière, A. J.: Études de philosophie grecque, París : Vrin, 1971.

Festugière, A. J.: Études de religion grecque et hellénistique, París: Vrin, 1972.

Festugière, A. J.: La vie espirituelle en Grèce à la époque hellénistique; ou les besoins de l'esprit dans un monde raffiné, París: Picard, 1977.

Hadot, P.: Bilan et pespectives sur les Oracles Chaldaiques, en Lewy H. Chaldean Oracles and theurgy, París, 1978, p. 702-720.

Hadot, P.: Les niveaux de conscience dans les états mystiques selon Plotin, en Journal de Psychologie, 1980, vol. 2-3, p. 243-266.

Hadot, P.: Qu'est ce que la philosophie antique?, París : Gallimard, 1995.

HAdot, P.: Plotin ou la simplicité du regard, París : Gallimard, 1997 (Trad. española de Solana M.: Ploino o la simplicidad de la mirada, Barcelona: Alpha Decay, 2004).

HeidegGer, M.: Hacia la pregunta del ser, en Acerca del nihilismo, Barcelona: Paidós, 1994 (Trad. española de Molinuelo J.L.).

Places, E. Des.: Syngeneia: La parenté de l'homme avec Dieu d'Homère à la Patristique, París : C. Klincksieck, 1964.

Places, E. Des.: La religión de Jamblique, en De Jámblique à Proclus, Genève, 1975, p.69-94. 
Ross, D.: Teoría de las ideas de Platón. Madrid: Cátedra, 1997 (Trad. española de Díez Arias J.L.) .

SAFFREY, H. D.: Quelques aspects de la spiritualité des philosophes néoplatoniciens. De Jamblique à Proclus et Damascius, en RSPh, 1984, vol. 68, p. 169-182.

SAFrReY, H. D.: Recherches sur le néoplatonisme après Plotin, París : Vrin, 1990.

SHAw, G.: Theurgy and the Soul. The neoplatonism of Iamblichus, Pennsylvania: Pennsylvania State Univ. Press, 1995.

Troulllard, J.: L'Un et l'âme selon Proclos, París : Les Belles Lettres, 1972.

ZAMORA, J.M.: La génesis de lo múltiple: materia y mundo sensible en Plotino, Valladolid, 2000.

María Jesús Hermoso Félix

Universidad Complutense de Madrid mjhermosofelix@yahoo.es 